\title{
MELHORIA DA QUALIDADE DA ÁGUA DO PERÍMETRO RURAL DE PINHALZINHO/SC
}

\author{
Gilmar de Almeida Gomes ${ }^{1}$
}

Naraiana Bovenschulte ${ }^{2}$

\author{
Carolina Franchini ${ }^{3}$
}

\section{RESUMO}

A crescente demanda pelos recursos naturais vem trazendo desequilíbrios ambientais. Águas superficiais e subterrâneas vêm recebendo grandes cargas de contaminação que comprometem sua qualidade. Este trabalho avaliou a qualidade da água de reservatórios comunitários do perímetro rural da cidade de Pinhalzinho-SC. Foram realizadas análises microbiológicas (coliformes totais e fecais) e físico-químicas (cloreto, sólidos e pH). Os resultados de 2013 mostraram que todos os reservatórios possuíam, no mínimo, um resultado fora do padrão, assim mostrou a a necessidade do tratamento dessa água para melhorar a sua qualidade e, por consequência, não gerar problemas de saúde a quem a consome. Confrontando esses resultados com os obtidos em 2014, nota-se melhora na qualidade da água, o que mostra uma maior conscientização. Para autonomia dos responsáveis é de suma importância que sejam treinados. Além disso, o consumidor deve estar ciente da qualidade da sua água.

PALAVRAS-CHAVE: Água, perímetro rural, tratamento.

\section{IMPROVEMENT OF WATER QUALITY OF THE PERIMETER OF RURAL PINHALZINHO / SC}

\footnotetext{
${ }^{1}$ Professor Doutor do Departamento de Engenharia de Alimentos da UDESC. gilmargomess@yahoo.com.br

${ }^{2}$ Acadêmico (a) do Curso de Graduação em Engenharia de Alimentos. naraboven@gmail.com

${ }^{3}$ Acadêmico (a) do Curso de Graduação em Engenharia de Alimentos. carol slo@hotmail.com
} 


\begin{abstract}
The growing demand for natural resources has brought environmental imbalances. Surface and groundwater have been receiving huge loads of contamination compromising their quality. This study evaluated the quality of the rural community reservoir perimeter of the city of Pinhalzinho-SC water. Microbiological analyzes (total and fecal coliforms) and physico-chemical (chloride, solids and $\mathrm{pH}$ ). The results of 2013 were carried out show that all reservoirs have at least one result outside the standard, so it takes the need the treatment of this water to improve its quality and therefore not lead to health problems who consumes. Comparing these results with those obtained in 2014, note improvement in water quality, which shows popular awareness. Responsible for autonomy is paramount that are trained. In addition, the consumer must be aware of the quality of your water.
\end{abstract}

KEY-WORDS: Water, rural perimeter, treatment.

\title{
MEJORA DE LA CALIDAD DEL AGUA DEL PERÍMETRO DE RURAL PINHALZINHO / SC
}

\section{RESUMEN}

La creciente demanda de recursos naturales ha provocado desequilibrios ambientales. Superficiales y subterráneas han estado recibiendo enormes cargas de contaminación que comprometen su calidad. Este estudio evaluó la calidad de la rural perímetro del depósito de la comunidad de la ciudad del agua Pinhalzinho-SC. Los análisis microbiológicos (coliformes totales y fecales) y físico-químicos (cloro, sólidos y pH) .El resultados de 2013 se llevaron a cabo, muestran que todos los embalses tienen por lo menos un resultado fuera de la norma, por lo que toma la necesidad el tratamiento de esta agua para mejorar su calidad y, por tanto, no conduce a problemas de salud que consume. Comparando estos resultados con los obtenidos en 2014, tenga en cuenta la mejora en la calidad del agua, lo que demuestra la conciencia popular. Responsable de la autonomía es de suma importancia que se entrenó. Además, el consumidor debe ser consciente de la calidad de su agua.

PALABRAS-CLAVE: El agua, perímetro rural, tratamiento.

\section{INTRODUÇÃO}

Atualmente, fala-se muito sobre ecologia, meio ambiente e manejo sustentável dos recursos naturais renováveis. Porém, somente uma pequena parte da população possui conhecimento suficiente para entender a dinâmica e as relações que ocorrem entre os diferentes ecossistemas que existem no mundo e a total dependência que todos temos com o meio ambiente (SCHNEIDER, 2013).

A falta de água já não é mais um problema distante da realidade, Nos últimos meses estamos presenciando que em São Paulo, por exemplo, esse fato já está presente na vida da população. O sistema Cantareira, que é o principal distribuidor de água para a grande São Paulo, está com o nível de suas represas muito baixo, o que está comprometendo a distribuição de água para a população e vem ocorrendo a 
meses sem previsão de melhora. Os recursos hídricos estão se tornando cada vez mais o centro das atenções do mundo (Wandscheer, 2010). Os mesmos encontramse em abundância no planeta, porém o grande problema está na distribuição e na qualidade. Tem - se ainda a ideia errônea de que água pura deve ser, simplesmente, incolor, inodora e insípida. Todavia um dos indicadores da qualidade da água são os coliformes, tanto fecais quanto totais (Duarte, 2011). Estes não são vistos a olho nu e não alteram as características organolépticas da água. Além disso, altas concentrações de íons também não são perceptíveis a olho nu e trazem grandes problemas a quem consome.

A água é o recurso renovável mais abundante no planeta, porém o descuido e o uso irracional vêm colocando em risco a potabilidade da mesma, fazendo com que água com qualidade torne-se um problema. A água para consumo humano deve atender requisitos de potabilidade para que não traga problemas a quem a consome, porém, muitos não possuem esse conhecimento.

A região Oeste Catarinense vem desenvolvendo-se muito nas últimas décadas, e assim tem-se uma maior necessidade de exploração dos recursos naturais e como consequência maior produção de lixo e esgoto, maior utilização de fertilizantes e defensivos agrícolas, este impacto também é manifestado na água tornando-a imprópria e colocando em risco a saúde dos usuários.

A água possui diversas fontes de contaminação desde sua captação até a distribuição na tubulação para o consumo. Essa contaminação altera a qualidade da água, tornando-a imprópria para o consumo humano, porém, essa contaminação, muitas vezes, não é visível necessitando, assim de análises de monitoramento constante d qualidade da água consumida.

Entre os agentes de desinfecção, o mais utilizado é o cloro, pois: é facilmente disponível como gás, liquido ou sólido, é barato, deixa um residual em solução de concentração facilmente determinável, é capaz de destruir a maioria dos microorganismos patogênicos; porém apresenta algumas desvantagens, porque é um gás venenoso e corrosivo, pode causar problemas de gosto e odor. Devido às normas de segurança e porque é mais fácil de aplicar o hipoclorito de sódio é a alternativa mais adequada (RICHTER, 2009). 
O munícipio de Pinhalzinho/SC possui uma grande parcela de sua população situada no perímetro rural e ali o abastecimento de água é realizado através de reservatórios comunitários. $\mathrm{Na}$ área rural a água não recebe o mesmo cuidado que a urbana, mostrando a necessidade de analisar e tratar essa água.

\section{DESENVOLVIMENTO}

Este trabalho tem como área de estudo o perímetro rural de Pinhalzinho, cidade localizada no oeste de Santa Catarina.

Na Figura 01 são demonstrados os pontos de coleta, todos situados no perímetro rural, onde os produtores não recebem água tratada em suas propriedades. Cada ponto indica um reservatório onde foram realizadas coletas de amostras de água.

Figura 01: Pontos de coleta de amostras de água no perímetro rural de Pinhalzinho-SC

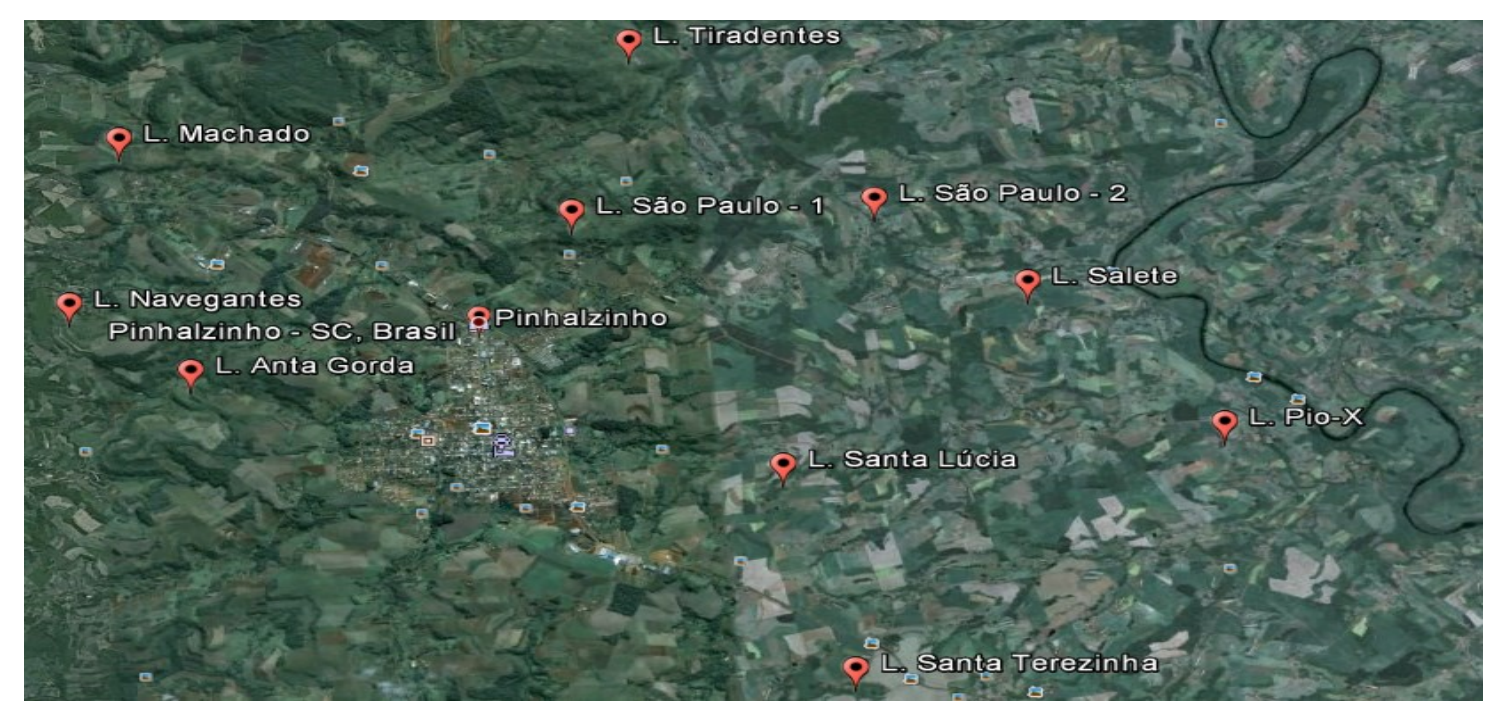

Fonte: BULEGON, 2013.

Foram coletadas amostras de água nos reservatórios, segundo a metodologia descrita pelo Manual Prático de Análise de Água da FUNASA (Fundação Nacional de Saúde), e CONAMA (Conselho Nacional do Meio Ambiente). As análises microbiológicas: coliformes fecais e coliformes totais e físico-químicas: concentração 
de cloreto, $\mathrm{pH}$, turbidez e os sólidos totais, foram realizados seguindo a metodologia proposta pelos órgãos acima citados.

\section{ANÁLISE E DISCUSSÃO}

$\mathrm{Na}$ tabela 01 apresentam-se os resultados para as análises microbiológicas das amostras de água coletadas nos reservatórios comunitários nos anos de 2013 e 2014.

Tabela 01: Resultados de coliformes totais e fecais de 2013 e 2014 nos 9 pontos de coleta.

\begin{tabular}{|l|c|c|c|c|}
\hline RESERVATÓRIOS & $\begin{array}{l}\text { Coliformes } \\
\text { totais } \\
\text { (NMP/100mL) }\end{array}$ & $\begin{array}{l}\text { Coliformes } \\
\text { totais } \\
\text { (NMP/100mL) }\end{array}$ & $\begin{array}{l}\text { Coliformes } \\
\text { fecais } \\
\text { (NMP/100mL) }\end{array}$ & $\begin{array}{l}\text { Coliformes } \\
\text { fecais } \\
\text { (NMP/100mL) }\end{array}$ \\
\hline Reservatório 01 & 2013 & 2014 & 2013 & 2014 \\
\hline Reservatório 02 & 16 & $>16$ & 9,2 & 2,2 \\
\hline Reservatório 03 & 16 & Ausência & 9,2 & Ausência \\
\hline Reservatório 04 & Ausência & 5,1 & 5,1 & Ausência \\
\hline Reservatório 05 & $>16$ & 16 & 0 & Ausência \\
\hline Reservatório 06 & 16 & $>16$ & 5,2 & Ausência \\
\hline Reservatório 07 & 16 & $>16$ & 9,2 & 2,2 \\
\hline Reservatório 08 & $>16$ & Ausência & $>16$ & 9,2 \\
\hline Reservatório 09 & 2,2 & 9,2 & 2,2 & Ausência \\
\hline
\end{tabular}

Fonte: SEPE, 2014.

Os coliformes são bactérias que normalmente residem nos intestinos dos animais superiores e a sua presença na água indica a possibilidade de contaminação por esgoto doméstico (RICHTER; NETTO, 1991, p. 37). No caso da presença na água do perímetro rural, pode indicar a presença de adubação com dejetos de animais (BULEGON, 2013).

Conforme a legislação CONAMA, a água para ser considerada potável deve apresentar ausência de coliformes totais e fecais em $100 \mathrm{ml}$ de água. Na tabela mostrada anteriormente, verificamos que os índices de coliformes totais, na sua grande maioria, obtiveram relevante melhora, sendo apenas os reservatórios 1, 4, $6 \mathrm{e}$ 7 os que apresentaram aumento no número de coliformes totais. Em relação aos coliformes fecais, apenas o reservatório 7 manteve-se no mesmo padrão, enquanto que todos os outros diminuíram significativamente o número de coliformes fecais, 
sendo que a grande maioria apresentou ausência desses indicadores de contaminação na análise de 2014.

$\mathrm{Na}$ tabela 02 apresentam-se os resultados para as análises físico - químicas das amostras de água coletadas nos reservatórios comunitários nos anos de 2013 e 2014.

Tabela 02: Resultados de cloreto, pH e sólidos de 2013 e 2014 dos 9 pontos de coleta

\begin{tabular}{|l|c|c|c|c|c|c|}
\hline RESERVATÓRIOS & $\begin{array}{c}\text { Cloreto } \\
(\mathbf{m g} / \mathbf{L})\end{array}$ & $\begin{array}{c}\text { Cloreto } \\
(\mathbf{m g} / \mathbf{L})\end{array}$ & $\mathbf{p H}$ & $\mathbf{p H}$ & $\begin{array}{c}\text { Sólidos } \\
(\mathbf{m g} / \mathbf{L})\end{array}$ & $\begin{array}{c}\text { Sólidos } \\
(\mathbf{m g} / \mathbf{L})\end{array}$ \\
\hline & 2013 & 2014 & 2013 & 2014 & 2013 & 2014 \\
\hline Reservatório 01 & 8,51 & 3,372 & 5,93 & 5,94 & 1 & 3 \\
\hline Reservatório 02 & 80,83 & 5,502 & 5,88 & 7,59 & 1,5 & 9 \\
\hline Reservatório 03 & 9,22 & 5,68 & 5,71 & 6,42 & 5,9 & 3 \\
\hline Reservatório 04 & 9,93 & 6,035 & 7,83 & 7,17 & 5,4 & 6 \\
\hline Reservatório 05 & 8,5 & 5,147 & 7,9 & 7,41 & 1,8 & 8 \\
\hline Reservatório 06 & 9,22 & 6,035 & 7,5 & 7,37 & 8 & 20 \\
\hline Reservatório 07 & 7,8 & 6,035 & 7,67 & 7,54 & 3,52 & 7,6 \\
\hline Reservatório 08 & 8,95 & 3,017 & 8,49 & 8,36 & 1,42 & 9 \\
\hline Reservatório 09 & 9,2 & 4,792 & 8,6 & 7,73 & 4,9 & 9 \\
\hline
\end{tabular}

Fonte: SEPE, 2014.

O teor de cloreto também é um indicador de poluição por esgoto doméstico, podendo conferir á água sabor salino e uma propriedade laxativa (RICHTER, NETTO, 1991, p. 33). No caso da presença em água do perímetro rural, pode indicar a presença de adubação com dejetos animais (BULEGON, 2013).

Os resultados obtidos em relação à concentração de cloreto também apresentaram diminuição nos resultados de 2013 para 2014, sendo que nenhum ponto se encontra fora dos padrões determinados segundo a legislação do CONAMA, que estabelece como o máximo permitido de cloreto na água $250 \mathrm{mg} / \mathrm{L}$.

Os valores de pH, os resultados de 2013 e 2014 mantiveram-se bem próximos. A legislação CONAMA estabelece que as medidas de $\mathrm{pH}$ devem estar entre 6,5 à 9,5, portanto os reservatórios 1, 2, e 3 apresentam-se fora dos padrões em 2013 e apenas os reservatórios 1 e 3 em 2014.

Segundo o CONAMA, a quantidade máxima de sólidos totais permitida é de $500 \mathrm{mg} / \mathrm{L}$. As análises de sólidos apresentaram aumento de 2013 para 2014 mas nenhum reservatório apresenta-se fora dos padrões estabelecidos. 
Nota-se, pelas tabelas, que a qualidade da água melhorou de 2013 para 2014. Alguns parâmetros já estão dentro dos padrões, isso se dá pela conscientização popular e pelo tratamento que os reservatórios receberam.

\section{CONCLUSÃO}

Os resultados deste estudo evidenciam que a água para consumo humano no perímetro rural não recebe o mesmo tratamento que o perímetro urbano.

O objetivo do estudo foi analisar e tratar a água de reservatórios comunitários do perímetro rural, essas ações foram realizadas e a qualidade da água melhorou. Entretanto, nem tudo aconteceu como planejado, pois trabalhos que envolvam vários segmentos da sociedade, poder municipal, representantes de grupos comunitários sociedade, responsáveis pelos reservatórios e universidade representam um espectro de interesse muito diferentes que devem estar focado num objetivo comum que é a melhora da qualidade da água, estas diciculdades também fizeram que o estudo se tornasse e ainda mais eficiente em sua realização. O importante foi a mudança obtida, tanto objetiva (tratar a água), quanto subjetiva (conscientização popular).

É necessária uma abordagem sistêmica para que os poderes públicos resolvam a questão da qualidade da água no perímetro rural: análise, tratamento e treinamento contínuo dos responsáveis pelos reservatórios comunitários de forma ininterrupta para gerar uma conscientização e cultura da necessidade de ter-se água com qualidade.

\section{REFERÊNCIAS}

BULEGON. R; ZAMIANI,A. GOMES, G.D.A; Periódico eletrônico. Fórum Nacional da Alta Paulista, v. 08, n.02, 2012.

CONSELHO NACIONAL DO MEIO AMBIENTE - CONAMA. Resolução $\mathbf{n}^{\circ} \mathbf{3 5 7}$ de 17 de março de 2005. Dispõe sobre a classificação dos corpos de água e diretrizes ambientais para o seu enquadramento, bem como estabelece as condições e padrões de lançamento de efluentes. Ministério do Meio Ambiente, 2005. 
DUARTE, Paula B. Microrganismos indicadores de poluição fecal em recursos hídricos, Belo Horizonte - MG, 2011. Disponível em: <http://www.microbiologia.icb.ufmg.br/monografias/158.PDF>. Acesso em: 20 ago. 2014.

FUNASA. Fundação Nacional de saúde. Manual Prático de Análise de Àgua. Acessoria de comunicação e educação em saúde. Brasília/DF. Disponível em:WWW.funasa.gov.br Acesso em 04/08/2014.

GOMES,G.A. etal. Estudo comparativo do fluxo químico hidrológico em diferentes áreas no município de Pinhalzinho. In: Congresso de iniciação científica e pós-graduação, 2010, FlorianópolisSC. Graduação, 2010. V.1. p. 60-61.

NUVOLARI, Ariovaldo et al. Reúso da Água: conceitos, teorias e práticas. 01. ed. São Paulo: Blucher, 2007.

PAGANINI, W.S. Poluição difusa e corpos d'água: ação silenciosa e desastres anunciados, São José dos Campos, 20 mar.2013. Acesso em 15 jan.2014. Online. Disponível em: http://www.cbdnat.com.br/trabalhos/

RICHTER, Carlos T. Tratamento de água: Tecnologia Atualizada. Editora Edgard Blucher. São Paulo 2003.Disponível em:WWW.scielo.com.br .Acesso em 20/09/2014.

REBOUÇAS, Aldo da C. Água e desenvolvimento rural. Estud. av. São Paulo, v. 15, n. 43. dez. 2001. SEPE, encontro de ensino, pesquisa e extensão. CEO - UDESC, 2014.

SOUZA, S. A. de. Água juridicamente sustentável: Um estudo sobre a educação ambiental como instrumento de efetividade do programa de conservação e uso racional da água nas edificações de Curitiba/PR. Revista Meio Ambiente e Sustentabilidade, v. 1, n. 1, 2012.

STUKEL, T. A, GREENBERG, E.R, DAIN, B.J, REED, F.C, JACOBS, N.J. A longitudinal study of rainfall and coliform contamination in small community drinking water supplies.Environ Sci Technol 1990;24:571-5.

UNIVERSIDADE FEDERAL DE VIÇOSA. Qualidade da água. Disponível em: <http://www.ufv.br/dea/lqa/qualidade.htm>: Acesso em: 01 set. 2014.

WANDSCHEER, Elvis. A escassez de água no mundo. ljuí-RS, 2003. Disponível em: <http://www.economiabr.net/colunas/wandscheer/agua.html>. Acesso em: 01 set.. 2014. 